Papers and Abstracts of Papers read at the Annual Scientific Meeting of the Society held on 23rd and 24th July 1965 at Stoke Mandeville Hospital, Aylesbury, England.

\title{
A STUDY OF THE SPACE REQUIREMENTS OF WHEELCHAIR USERS
}

By Professor W. F. Floyd, Dr. L. Guttmann, Mr. C. Wycliffe Noble, Miss K. R. PARKES and Mrs. J. WARD

College of Technology, Loughborough, and National Spinal Injuries Centre, Stoke Mandeville, Aylesbury, England

(Paper presented by Miss Parkes)

NinETY-ONE male and 36 female patients at the National Spinal Injuries Centre, Stoke Mandeville, were the subjects of a study to determine the functional anthropometry of wheelchair users.

Apparatus was designed to measure on these subjects nine standard anthropometric body dimensions and 35 comfortable and maximum reaching distances at different angles and at varying heights from floor level. Other relevant details, e.g. subject's age, nature of injury, type of chair used, etc., were also recorded.

The data were analysed by computer to derive means and 5 th and 95 th percentile values for the male and female groups. From these values it was possible to construct diagrams of use to the architect and designer for determining space requirements for this category of disabled people.

\section{THE MONOTUBULAR CALIPER FOR PARAPLEGIC PATIENTS}

\author{
By L. Pierquin, M.D., P. Dollfus, M.D. and G. Fajal \\ Institut Régional de Réadaptation du Nord-Est Nancy, France
}

ONE has always tried to reduce the weight and cumbersomeness of the calipers for paraplegic patients; nevertheless the essential qualities of solidity and function should be respected.

We propose the use of monotubular calipers, made out of one single support, the external one, consisting of a metal tube of drawn steel (fig. I). The first results have been satisfactory. One can add to this the ease with which they can be put on and removed in addition to comfort and security in ambulation. Moreover, the manufacturing of such calipers is easy, the cost lower than that of a usual conventional caliper.

Description. From the front, the monotubular caliper is straight, does not follow the curves of the lower limb, neither the axis of the thigh or leg (fig. 2).

Seen from the side, the caliper is absolutely straight, connected to the shoe by a pivot-pin placed in front of the axis of the limb (fig. 3), the effect of which is the creation of a triangle as basis for weightbearing which is important for the 

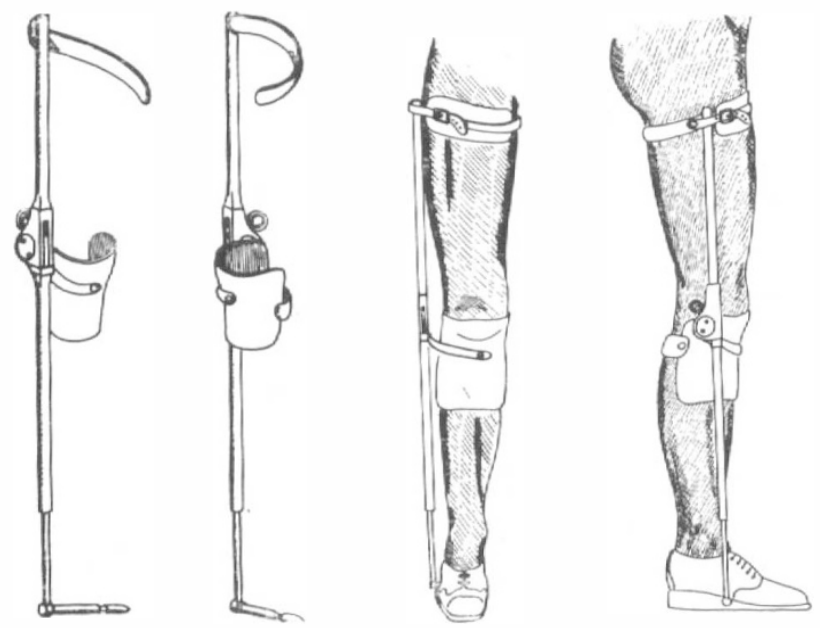

FIG. I-FIG. 3

anterior-posterior balance of the body when standing and walking (fig. 4). The anterior part of the triangle, the caliper, has a variable length and resistance due to a telescopic shock-absorbing system; the posterior part of the triangle is represented by the axis of the limb. This triangle, during the act of walking modifies itself when the telescopic mechanism comes into play (fig. 4). The pivot-pin is placed in the posterior half of the middle part of the shoe sole, forward in the case of a paralysed foot, backwards in a normal foot. Flexion and extension of the foot can be limited, when needed, by a stop of the PERLSTEIn type. The caliper is fixed to the pivot-pin by the telescopic shock-absorbing system, consisting of a cylindrical spring shortening or lengthening itself according to the vertical pressure, but also allowing a certain rotation of the foot. The pivot-pin is secured in the shoe by a steel ball check. The leg part of the caliper is attached to the limb by a large knee-

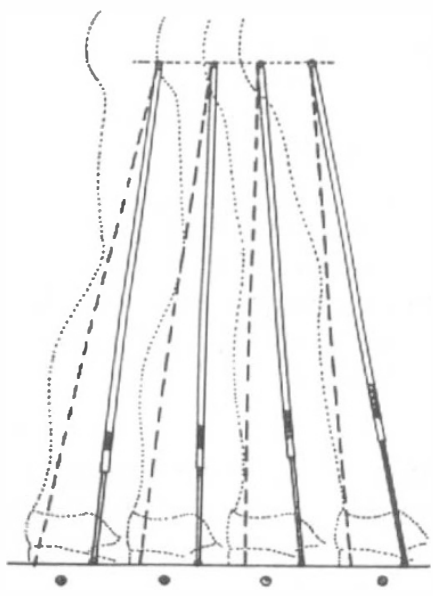

FIG. 4

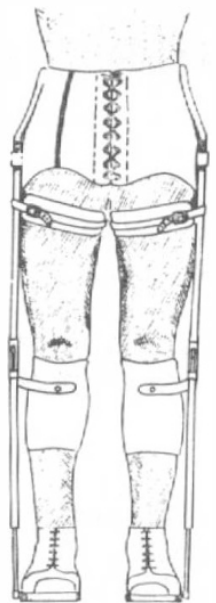

FIG. 5 
cap, made out of plastic material (polythene, araldite) modelled from a plaster cast, the circumference of which, extending backwards, encloses the condyles of the femur and tibia, thus resembling a prosthesis. This knee-cap is attached to the caliper by a steel band welded below the knee articulation, situated in a plan slightly inclined towards the front. The knee articulation is of the fork-joint type and the extension is limited backwards by a check. Unlocking is easily managed by pulling on a ring. The upper part of the brace is connected to the thigh by a thigh band.

This monotubular caliper is at present used in cases of flaccid and spastic paraplegia, when necessary connected to a pelvic band or in high lesions to a corset of plastic material with tubular reinforcements to maintain a strong support in the frontal plane and connected to the braces by a sliding block allowing, when needed, either complete or partial blocking (fig. 5).

The main advantages of this type of caliper for paraplegics are:

(i) the lightness, already noticeable in these calipers made out of steel, approximately 200 grams less than a conventional duraluminium apparatus; this will be even less as experiments on light material are carried out;

(ii) the ease of application and removal;

(iii) short delays of manufacturing;

(iv) good correction, with the minimum of pressure, of genu valgum formation;

(v) its great flexion range allows walking on the knees and sitting with ease.

\section{SUMMARY}

A monotubular caliper is presented, made out of a tube of drawn steel. It is lighter than a classical type of caliper, solid, safe, easy to put on and remove. Pressure points have been reduced to a minimum. Manufacturing is easy and delays shorter.

\section{RÉSUMÉ}

Une attele monotubulaire est présentée, faite d'un tube d'acier étiré. Elle est plus légère que les attelles classiques, solide, sûre, aisée à mettre et à enlever. Les points de pression ont été reduits au minimum. La fabrication est facile et les délais plus courts.

\section{ZUSAMMENFASSUNG}

Ein monotubulärer Gehapparat aus Stahl wird beschrieben. Er ist leichter als der übliche Typ von Apparaten, solide und sicher und ist leicht anzulegen und abzunehmen. Druckpunkte sind zu einem Minimum reduziert, und die Fabrikation ist einfach und braucht weniger Zeit.

\section{Discussion}

Kerr, W. G. (Scotland), said that the caliper just seen was in some way revolutionary in design. It was light-weight and would possibly be cheaper than calipers used in the past. There were, however, one or two points which should be very carefully considered before a rapid adoption. The principle of a caliper was a common orthopaedic one but it depended on three-point pressure: $(a)$ posterior point, $(b)$ anterior point, and $(c)$ stabilising point, which was more of a posterior one at the foot.

The strength of the spring for the foot piece might have to be varied, depending 
on the weight of the patient. With regard to the top, which would take posterior pressure, he did not think the two simple metal bearings would give sufficient protection to an anaesthetic skin and this he felt should be modified to give a much broader base for posterior pressure against the thigh. With regard to the knee piece, this was very similar in shape, design and method of construction to the new patellar tendon-bearing prosthesis for a lower limb amputee. The difference was that the amputee was taking all his weight in that section; it was weightbearing. In the paralysed person, for whom this splint had been constructed, this was not a weightbearing structure. Their experience with amputees was that the patient developed pressure at two major joints and of course the ordinary amputee could complain. If the amputation were for ulceration from spina bifida or osteomyelitis following spina bifida and the skin was anaesthetic, one could get into severe trouble because the patient did not feel pressure. One of the main points of pressure was the posterior aspect. When taking full weightbearing one must have good strong support behind to push the stump against the patellar tendon-bearing bridge. When working on the three-point pressure system there was no need for anything behind. The standard caliper worn by the majority of paraplegics had a soft leather front and possibly nothing behind at all. He thought experiments could be done on total elimination of this posterior portion.

Secondly, if one took another type of artificial limb, the more old-fashioned artificial limb or an ordinary caliper, there was the question of the siting of the joint of the caliper in relation to the knee joint. When one released the joint of the knee and let it bend, the actual knee joint of the body was moving in a different arc. One was liable to thrusts and pressure on the inner portion. This moved slightly on the metal frame. He did not know whether this was intended, but in one of the latest limbs they had been trying in Edinburgh for geriatric patients, as a temporary walking pylon for a below-knee, one gave them all the weightbearing at the top, rigged the bandage inside and fixed on a portion which swivelled on the front. He thought it might be considered having a swivel inserted on this caliper so that the front portion could move as the patient sat down. Of course, after application, as with any form of splint for paraplegics, it must be taken off and the skin inspected within an hour or two to see if there were any redness on the point of pressure, and he thought one would have to be very careful with this firmer device to make absolutely sure that it fitted carefully.

Dollfus, $P$., thanked Mr. Kerr for drawing attention to these points. The caliper was his own, which was experimental. To take up this point first - any type of plastic or leather support to prevent pressure could be adapted; even an ischial support in poliomyelitis could be adapted and moulded according to a plaster cast of the patients - therefore really giving a back support with minimal pressure. When the knee bent at the hinge, he agreed with Mr. Kerr there tended to be a slight pressure on the front, but this pressure corresponded to the ordinary pressure one would get in any ordinary caliper. Pressure was removed when the person was standing. The important thing one should see in this caliper was that the plastic moulding was made according to a plaster cast of the patient's knee. Therefore, when the patient was standing up this cast corresponded to the particular anatomical configuration of the patient's knee. There was no direct pressure on the knee as sometimes happened with a knee cap, especially over the patella. He had personally tried the caliper, and having very good sensation and being of French temper, if it did hurt, the workmen would hear about it immediately. The caliper was very comfortable indeed when one stood up. The problem remaining now was when the person was sitting down, because the direction of the femur and tibia then changed. However, he had not noticed any uncomfortable sensation whilst he was driving with it for five to six hours. He had no pain at all in his knee, but sometimes when he drove with an ordinary caliper he could very well feel some pressure at the end of the journey. However this would have to be studied, as it was still experimental. They had tried this caliper in 50 children and 20 paraplegics. They had had no pressure sores at all. Being paralysed himself, he thought it of a very interesting design. 
Maury, M. (France), asked whether in the monotubular caliper there was not a contra-indication when there was adduction and flexion spasm at the knees.

Dollfus, $P$., replied that they had not had any problems with flexion and adduction spasm at the knee. They had seen only patients with a tendency to flexion spasms at the knee, and the new design was as strong and equivalent to the conventional type of caliper in that respect.

Maury, M. (France), asked about the knee bending automatic device, which in this particular caliper was short.

Dollfus, $P$. agreed. There were different types on normal classical calipers-the Hoffer system or Swiss system-and when a person sat down the flexion of the caliper bent automatically at the knee hinge to allow the patient to sit. In this caliper, which they were actually trying on him, they thought they would adopt a $\frac{1}{2}$ Hoffer system to be able to catch the angle of the chair or seat so that automatically the caliper would bend in two at the hinge.

\title{
RESPIRATORY AND OTHER DEVICES FOR THE TOTALLY PARALYSED IN DOMICILIARY LIFE
}

\author{
By Dr. Margaret Agerholm, M.A., B.M., B.Ch. Oxon. \\ Nuffield Department of Orthopaedic Surgery, University of Oxford, England
}

\section{SUMMARY}

PERMANENT dependence on a mechanical respirator, even when associated with severe or total locomotor paralysis, does not preclude discharge from hospital to domiciliary life, provided certain equipment and facilities are provided. Much can be learnt from cases of lower motor neuron paralysis of the respiratory musclesusually caused by poliomyelitis and associated with severe locomotor disabilitywho have successfully established themselves at home and, step by step, overcome the difficulties created by their respiratory and locomotor paralyses.

The equipment and facilities which they need fall into three categories:

(a) Respiratory. They need not only the necessary basic equipment of respirator and, where necessary, sucker, but also a reliable system to ensure that errors in electricity supply, in the machines themselves, and in the connections and other accessories are easily, promptly and, if possible, automatically corrected. Provision should also be made for mobility of the patient and his equipment, so that he is not permanently confined to one room in one house. Adequate arrangements must be made for servicing the equipment at regular intervals and for rectifying faults.

(b) 'Care'. Wise selection of equipment and techniques for routine nursing and daily living activities greatly reduces the time and effort spent on them.

(c) Occupational and Recreational. These enable the patient and his family to live to maximum capacity within the limits of the physical disability: they may enable the patient himself to earn part or all of the necessary family income.

The importance of this final stage of rehabilitation in the management of the severely paralysed is stressed. 